\title{
Fundamentalismos evangélicos e guerras culturais em contextos africanos: o debate ao redor das leis anti-homossexualidade
}

Evangelical fundamentalism and culture wars in African contexts: the debate on anti-homosexuality laws

\section{Caterina Alessandra Rea}

\section{(2) OpenEdition Journals}

\section{Edição electrónica}

URL: https://journals.openedition.org/aa/8324

DOI: 10.4000/aa.8324

ISSN: 2357-738X

\section{Editora}

Programa de Pós-Graduação em Antropologia Social (UnB)

\section{Edição impressa}

Paginação: 127-151

ISSN: 0102-4302

\section{Refêrencia eletrónica}

Caterina Alessandra Rea, «Fundamentalismos evangélicos e guerras culturais em contextos africanos: o debate ao redor das leis anti-homossexualidade», Anuário Antropológico [Online], v.46 n.2 I 2021, posto online no dia 30 maio 2021, consultado o 03 junho 2021. URL: http:// journals.openedition.org/aa/8324 ; DOI: https://doi.org/10.4000/aa.8324

\section{(c) (i) (9)}

Anuário Antropológico is licensed under a Creative Commons Atribuição-Uso Não-Comercial-Proibição de realização de Obras Derivadas 4.0 International. 


\title{
anuário antropológico \\ v. $46 \cdot \mathrm{n}^{\circ} 2 \cdot$ maio-agosto $\cdot 2 \odot 21.2$
}

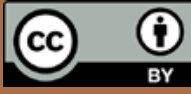

\section{Fundamentalismos evangélicos e guerras culturais em contextos africanos: 0 debate ao redor das leis anti-homossexualidade}

\author{
Evangelical fundamentalism and culture wars in African contexts: the debate on \\ anti-homosexuality laws
}

DOI: https://doi.org/10.4000/aa.8324

\section{Caterina Alessandra Rea}

Universidade da Integração Internacional da Lusofonia Afro-Brasileira, Instituto de Humanidades e Letras/Campus dos Malês, São Francisco do Conde, BA, Brasil

Professora adjunta do Instituto de Humanidades e Letras da Universidade da Integração da Lusofonia Afro-Brasileira, Campus dos Malês/Bahia. Doutora em Filosofia pela Université Catholique de Louvain (Bélgica), realizou pós-doutorado pelo Programa Interdisciplinar de Humanidades da Universidade Federal de Santa Catarina.

Prolongando a leitura da militante nigeriana Sokari Ekine, a propósito do conflito entre duas narrativas opostas da África queer, este texto mostra que estas narrativas correspondem aos dois polos opostos do que podemos chamar de "guerras culturais norte-americanas" (Kaoma, 2009). Apesar de serem mobilizadas por grupos políticos rivais - os líderes africanos que proclamam a não africanidade da homossexualidade e as ONGs internacionais que denunciam o fenômeno da "homofobia africana" - esses discursos mostram sua fragilidade ao apresentarem a África como uma realidade uniforme, encarnando o olhar neoimperialista e racista do Ocidente, que oculta a pluralidade das culturas e das vivências africanas. Esta compreensão, presente entre xs acadêmicos e militantes africanxs, que lutam pela dissidência sexual, será aqui entrelaçada com a leitura de Kapya Kaoma, que denuncia a exportação das guerras culturais estadunidenses e a ação de igrejas evangélicas ligadas à direita cristã norte-americana, em muitos países da África. A este propósito, torna-se necessário passar por uma breve apresentação da noção de guerras culturais mobilizada pela direita cristã estadunidense e por uma análise de suas pautas antigay. Articulando a tese de Kaoma com algumas das análises da crítica queer of color, tentaremos questionar a narrativa homonacionalista do excepcionalismo ocidental em matérias de gênero, sexualidades e democracia.
Extending a reading by the Nigerian activism Sokari Ekine, regarding the conflict between two opposite narratives of Queer Africa, this paper shows that both these narratives correspond to the two opposite poles of what that we can call "American culture wars" (Kaoma, 2009). Despite being mobilized by rival political groups - African leaders who proclaim the non-Africanity of homosexuality and international NGOs denouncing the phenomenon of "African homophobia" - these two speeches show their fragility in presenting Africa as a uniform reality and embody the neo-imperialist and fundamentally racist view of the West, which hides and ignores the plurality of African cultures and experiences. This understanding, present among African academics and activists, who fight for sexual dissidence, will here be interwoven with the reading of Kapya Kaoma, who have been denouncing, for several years, the exportation of U.S. culture wars and the action of Evangelical churches linked to the U.S. Christian Right in many African countries. So, it is necessary to shortly present the notion of Culture Wars, mobilized by the U.S. Christian Right and analyze its antigay agenda. We articulate Kaoma's thesis with some analysis from Queer of Color Critique, in order to question the homonationalist discourse of Western exceptionalism, concerning gender, sexualities, and democracy. 


\section{Introdução}

Um dos mais difundidos discursos com os quais se depara quem trabalha com temas das minorias sexuais no continente africano é o da não africanidade da homossexualidade, que produz formas de silenciamento e subordinação em relação aos relacionamentos e desejos entre pessoas do mesmo sexo neste continente. Este discurso tem sido frequentemente endossado por líderes religiosos e políticos, como Robert Mugabe, Yoweri Museveni ou arap Moi, que reivindicam uma postura nacionalista, anticolonial e crítica do mundo ocidental. Contudo, como sugere o estudioso sul-africano Thabo Msibi, "vale a pena pesquisar, aqui, a validade destas reivindicações pelas quais o desejo entre pessoas do mesmo sexo não é africano, é contra as religiões africanas e as leis africanas" (Msibi, 2011, p. 62) e questionar a "validade do mito de uma África 'sem sodomitas"' (Msibi, 2011, p. 63).

Neste texto, tentaremos problematizar esse poderoso discurso da não africanidade da dissidência sexual, avançando a hipótese de que ele poderia encarnar um legado da época colonial ${ }^{1}$. De fato, esse discurso vem sendo incorporado nas estratégias de muitas igrejas evangélicas africanas, que possuem vínculos políticos, além de teológicos, com igrejas evangélicas dos Estados Unidos e que representam os interesses da direita cristã norte-americana em sua exportação das guerras culturais (Kaoma, 2009; 2012).

A atual situação política no Brasil com a instauração de um governo de extrema direita, caracterizado por uma visão conservadora que retoma os discursos pró-família, antigênero, antigay e que afirma seu desprezo pelos direitos humanos, tem impulsionado as presentes reflexões. De fato, a política brasileira, hoje, não esconde seu alinhamento com os posicionamentos do evangelismo transnacional e nos induz a refletir sobre o impacto das guerras culturais estadunidenses e de sua extensão para diferentes regiões do Sul global. O vasto crescimento do evangelismo conservador, no Brasil e na América Latina, através da rede de igrejas evangélicas neopentecostais, que já em 1987, o jornalista Delcio Monteiro de Lima denominava "os Demônios [que] descem do Norte", desperta questões sobre o investimento da direita cristã estadunidense nestes territórios. Seguindo a perspectiva dos Estudos Feministas e Queer, especialmente a partir do lugar do Sul global, este texto visa discutir como as questões de gênero e sexualidade têm recentemente se tornado um terreno privilegiado de conflitos políticos, assim como, em muitos casos, o veículo de novos projetos imperialistas do Ocidente.

Nesse contexto, a posição do pastor zambiano Kapya Kaoma nos parece de extrema importância, ao apontar para o fenômeno das guerras culturais e para um eixo ainda pouco explorado do neoimperialismo estadunidense na África, ou seja, as agendas da direita cristã e do evangelismo norte-americano. Do ponto de vista metodológico, este trabalho apresenta uma leitura teórica da dissidência sexual e de gênero, na África, com foco nas produções de autorxs oriundxs de países de ex-colonização britânica. Não é nossa intenção apresentar uma reconstrução histórica ou antropológica sobre a dissidência sexual em contextos africanos, mas trabalhar com a produção de discursos por parte de atores sociais e políticos con-
Segundo Adriaan van Klinken e Ezra Chitando (2016), foram os colonizadores a implantar o regime da heterossexualidade obrigatória na África, através de uma estrita legislação penal que criminalizava a sodomia e reprimia os chamados atos sexuais contra a natureza. Em países de ex-colonização britânica, poder-se-ia então afirmar que esta defesa da heterossexualidade como a única expressão viável de relacionamento sexual aparece muito mais como uma herança dos valores vitorianos e cristãos dos colonizadores ingleses do que das próprias culturas africanas. 
temporâneos. Orientam-nos as leituras da Crítica Queer of Color, que entendem que a discussão sobre as sexualidades e os gêneros dissidentes nos abre para as principais questões do mundo contemporâneo e remete para as atuais tensões transnacionais entre Norte e Sul globais. A crítica queer of color adota a perspectiva da epistemologia descolonial, que contesta as marcas da colonialidade e do pensamento eurocêntrico presentes nas produções de conhecimento da epistemologia ocidental dominante. No campo do pensamento e da prática queer, trata-se de deixar aparecer as diversas epistemologias da sexualidade, irredutíveis ao modo ocidental da presença LGBT. Reportamos às palavras de três reconhecidxs pesquisadorxs no campo da crítica queer of color:

Um exame do impacto do apagamento das diferentes maneiras de ser se torna crucial nos contextos queer, pois o Ocidente é construído como o campeão progressista das subculturas queer globais. $\mathrm{O}$ racismo cultural nos circuitos queer funciona em relação com o imaginário cultural do Sul global como um lugar necessariamente homofóbico e produz códigos hegemônicos de colonialidade, que reúnem apoio aos empreendimentos neocoloniais e neoimperialistas, colocando o Norte global como o único garante dos direitos humanos para as pessoas, incluindo as mulheres e os sujeitos queer (Bakshi; Jivraj; Posocco, 2016, p. 1-2).

Sandeep Bakshi, Suhraiya Jivraj e Silvia Posocco declaram que, ao usar o termo Ocidente, pensam se referir a "configurações geopolíticas diferentes" (2016, p. 12), que os termos "Euro-América e Euro-Atlântico" (idem) poderiam melhor definir. Seguimos estes autores ao utilizar o termo Ocidente como uma abreviação geopolítica que investe os principais sistemas de dominação e "suas produções capitalistas/heteropatriarcais/ cristianizadas” (Bakshi; Jivraj; Posocco, 2016, p. 1).

Na perspectiva da descolonização das sexualidades e dos gêneros dissidentes, muitas lideranças africanas têm argumentado que é urgente que a África defina os seus próprios caminhos para discutir tais questões. Para isso, é preciso debater os principais discursos que têm polarizado o debate, ou seja, o da "África sem sodomitas” - o discurso majoritário nos contextos locais - e o da África como o lugar mais inóspito para ser homossexual - o discurso dos direitos humanos encampado pelas ONGs LGBT internacionais ${ }^{2}$. Como bem destaca a feminista do Malauí Jessie Kabwila, esses dois discursos são ambos "em grande parte de origem colonial" (Kabwila, 2013, p. 376). Nesta direção, é nossa intenção mostrar que esses dois discursos, aparentemente opostos e sustentados por grupos politicamente divergentes, encarnam, em ambos os casos, interesses neoimperialistas e coloniais do Ocidente, representando os dois polos das guerras culturais norte-americanas.

É importante, porém, observar, desde o começo, que não queremos com isso simplesmente reverter o argumento da não africanidade da homossexualidade, reivindicando que a homofobia - e não a homossexualidade - seria algo importado e derivado unicamente das heranças coloniais. Um tal argumento incorre no risco de perpetuar mitos das origens, que apresentam um "antes" paradisíaco
2 Sobre a ação das ONGs LGBT internacionais e a intervenção política de países neoliberais do Norte em vários contextos africanos, cfr. Awondo, 2019. Evocando as "tensões pós-coloniais" (Awondo, 2019, p. 32) que tais intervenções acarretam, Patrick Awondo questiona os "usos políticos de uma cartografia das homofobias [...] elaborada no hemisfério norte, pelos líderes das democracias liberais" (Awondo, 2019, p. 33) que espalham o discurso único da homofobia africana. 
e perfeito, que tem pouca chance de corresponder à realidade. O que queremos dizer é unicamente que a ideia da monosexualidade rigorosamente heterossexual dos povos africanos (e em geral pós-coloniais) é sim um mito, cujas raízes estão na história da colonização e de suas heranças (Hoad, 2007; Awondo, Geschiere, Reid, 2013). Certo é que as representações coloniais sobre as sexualidades e o gênero de africanos e afrodescendentes são mais complexas e não se limitam a esta versão do que chamamos de mito da monosexualidade heterossexual dos africanos. Pensamos, a este propósito, nas reflexões de feministas negras norte-americanas que relatam que o culto da masculinidade e o heterossexismo dos homens nas comunidades negras seria o efeito de um imaginário colonial invertido, a afirmação de uma humanidade negada e vilipendiada através da emasculação e da feminilização dos homens colonizados e escravizados. Assim, a presença da dominação masculina nas comunidades negras foi apagada e ignorada na visão da sociedade hegemônica branca, para quem "os homens negros teriam sido 'castrados', [que] o principal trauma da escravidão era o de ter privado os homens negros do direito ao privilégio e poderes masculinos, de tê-los impedido de atualizar plenamente a 'masculinidade"' (bell hooks, 2013, p. 161).

No contexto escravocrata da medicina colonial, assim como na retórica racista mais recente, os homens negros são apresentados como castrados e desvirilizados, enquanto as mulheres são enxergadas como violentas, dominadoras e viris (Dorlin, 2010). Esta suposta organização familiar, "na qual a ordem dos sexos seria invertida” (Dorlin, 2010, p. 70) em relação à norma da masculinidade e da feminilidade brancas e dominantes, é o que foi chamado de matriarcado negro. O mito do matriarcado negro é objeto de críticas e questionamentos por parte de várias feministas negras norte-americanas (bell hooks, 2019; Davis, 2016; Collins, 2019). O principal exemplo da persistência deste mito na sociedade norte-americana é o Relatório Moynihan, intitulado The Negro Family, publicado pelo governo estadunidense em 1965. Conforme relata Angela Davis, este documento "relacionava diretamente os problemas sociais e econômicos da comunidade negra da época à suposta estrutura familiar matriarcal” (Davis, 2016, p. 25) e à crença da "ausência de autoridade masculina entre o povo negro" (Davis, 2016, p. 26). Tais ideias não envolvem diretamente a discussão sobre a hetero/homossexualidade dos negros, embora elas possam implicar uma certa aproximação da mulher negra masculinizada e agressiva com a lésbica (Collins, 2019). Nestas representações coloniais e racializantes, a sexualidade dos homens e, sobretudo, das mulheres afrodescendentes é apresentada como uma sexualidade desviante, aberrante e inadequada (Collins, 2019; bell hooks, 2019). Reencontramos, por outra parte, a ideia da heterossexualidade - embora hipersexualizada e perversa - dos corpos racializados nas mais recentes representações homonacionalistas, analisadas pela teórica Jasbir Puar no contexto do pós 11 de setembro, que opõem a branquitude queer à suposta heterossexualidade dos grupos racializados (Puar, 2007 e 2015). "Olhando retrospectivamente, a partir do 11 de setembro, o meu interesse centrava-se no período de 40 anos da era pós-direitos civis que, através da política de inclusão liberal, continua a produzir o outro sexual como branco e o outro racial 
como heterossexual" (Puar, 2015, p. 300).

Por nossa parte, gostaríamos de evidenciar a pluralidade das vivências sexuais e de gênero africanas, para além da reivindicação de uma suposta pureza unicamente heterossexual, mas também da afirmação da suposta inexistência originária da homofobia no continente africano. Se a perspectiva descolonial aponta para a influência da colonização na forma de forjar o gênero e a sexualidade dos grupos colonizados, incluindo a imposição do heteropatriarcado (Lugones, 2014; Bacchetta; Maira; Winant, 2019), gostaríamos, por nossa parte, de fazer a hipótese da existência de uma homofobia "de baixa intensidade" - para retomar a expressão da antropóloga argentina, Rita Segato, sobre a presença, no mundo pré-colonial de um "patriarcado de baixa intensidade" (Segato, 2011, p. 32) - que teria sido investida e transformada pelas normas coloniais no campo do gênero e da sexualidade.

\section{A trama das guerras culturais: entre Estados Unidos e África}

O texto da militante nigeriana Sokari Ekine, publicado no Queer African Reader, é extremamente incisivo sobre a presença das duas narrativas que os militantes queer do continente têm que enfrentar e superar para afirmar suas lutas e reivindicações. Escreve Sokari Ekine, no início do texto:

Duas narrativas distintas, porém, interligadas dominam as discussões sobre as sexualidades queer africanas. Uma afirma que as sexualidades queer são "não africanas", enquanto a outra trata a África como um lugar de homofobia obsessiva. A primeira provém de um conjunto de fundamentalismos religiosos, que insistem em interpretações estritamente literais de textos religiosos, e uma postura culturalmente essencialista, que patologiza e nega a existência da condição queer (queerness) no continente (...) A segunda narrativa sobre a "homofobia Africana" está enraizada em discursos coloniais sobre uma sexualidade africana desviante e peculiar, e em uma agenda LGBT contemporânea neoliberal e global, que tenta universalizar normas sexuais e de gênero brancas e euro-americanas (Hoad, 2007, p. xii; Massad, 2007; Atluri, 2009) (Ekine, 2013, p. 78).

Ao rejeitar essas duas narrativas, Sokari Ekine nos adverte do fato de que ambas perpetuam uma imagem homogênea e estática da África, que não encarna a realidade de um continente diverso, rico culturalmente e plural, também em suas expressões da sexualidade e das lutas ao redor da dissidência sexual e de gênero. De fato, as duas narrativas, que manifestam duas possíveis versões dos nacionalismos sexuais, são muito mais próximas do que poderia parecer a partir de uma leitura superficial. Seria errado acreditar que o heteronacionalismo manifestado na primeira narrativa seja originariamente africano, enquanto somente o homonacionalismo da segunda seria uma importação do Ocidente. O que queremos afirmar é que as duas expressões do nacionalismo sexual, o heteronacionalismo, 
que pretende negar a existência da dissidência sexual na África e afirmar sua incompatibilidade com a africanidade, e o homonacionalismo que denuncia a homofobia africana, são expressões e faces do imperialismo ocidental.

Em outro texto, publicado em 2016, Sokari Ekine reflete sobre as legislações anti-homossexualidade de vários países africanos, cujos efeitos são a criminalização e a negação dos direitos básicos de cidadania para as pessoas dissidentes sexuais. A impressão é que, segundo a autora, atrás dos discursos inflamados de políticos africanos como Museweni ou Mugabe, esteja uma tácita aceitação do "imperialismo religioso" do evangelismo norte-americano, ao mesmo tempo em que esses homens políticos levantam a bandeira do anti-imperialismo, ao rejeitarem a lógica "ocidental" dos direitos humanos e LGBTI. Escreve Sokari Ekine a este propósito:

Os líderes religiosos e políticos africanos erram em realizar, ou escolhem ignorar, as contradições ideológicas que utilizam para apoiar o policiamento dos cidadãos queer. Por exemplo, a disposição com a qual Museweni de Uganda aceita o imperialismo religioso, mas não, como ele próprio recentemente afirmou, o 'imperialismo social'. De maneira similar, a ironia de um tirano como Robert Mugabe, empolgado com o imperialismo religioso, na presença dos evangélicos estadunidenses e, ao mesmo tempo, querendo ser o exemplo de anti-imperialismo (Ekine, 2016, p. 20).

Com certeza, continua Sokari Ekine, uma tal hipocrisia não é somente dos governos africanos, pois os democratas americanos, como Barak Obama, que por um lado reivindicam a defesa dos direitos LGBT e sua exportação pelo mundo, não conseguem, entretanto, ou não se engajam o suficiente para deter os evangélicos estadunidenses no seu projeto de espalhar ódio e discursos homofóbicos não somente nos Estados Unidos, mas também no Sul global (Ekine, 2016). Sokari Ekine toca, aqui, no ponto nodal da questão: atrás da homofobia de Estado e do heteronacionalismo afirmado em vários países africanos, estão imposições ocidentais, ou mesmo, preceitos bíblicos e cristãos, mais do que as tradições supostamente arcaicas e pré-modernas dos povos africanos. De fato, se "começamos a olhar para além do ódio, encontramos uma autoconsciência colonial subjacente a imposições do Ocidente. Isso leva à defesa de uma cultura africana fixa e de noções bíblicas (ou corânicas) fixas da sacralidade do heterossexual" (Ekine, 2016, p. 20). O pânico moral ao redor das minoras sexuais, que atravessa vários países africanos, afunda boa parte das suas raízes no fundamentalismo cristão fomentado, em particular, por vertentes evangélicas estadunidenses, defensoras de uma visão conservadora heteropatriarcal. Como escreve ainda a militante nigeriana:

Há suficientes evidências para mostrar que o pânico moral contra a população LGBTI é uma campanha sistemática e bem-organizada de um lado ao outro do continente, que expõe as relações entre o fundamentalismo religioso, cultural e nacionalista, líderes corruptos e os fortes laços internacio- 
nais com os evangélicos estadunidenses que abraçam os mesmos ataques contra xs queers nos Estados Unidos e contra qualquer um(x) que não se encaixe na ordem heteropatriarcal. O envolvimento de grupos evangélicos estadunidenses está bem documentado, em particular, grupos como Exodus International, Prison Fellowship, ou Family Research Council, e o American Center for Law and Justice, todos os quais têm promovido ativamente legislações anti-homossexuais, em vários países (Ekine, 2016, p. 21).

Que a chamada "homofobia africana" e, mais geralmente, a "politização da homossexualidade” (Kaoma, 2016), na maioria dos países da África Subsaariana, tenha raízes mais profundas e externas ao continente africano e às suas culturas é uma hipótese instigante, que pode abalar a "história única" (Macharia, 2010; Ndashe, 2013) de tal homofobia. A influência do fundamentalismo evangélico, ligado à direita cristã norte-americana, cuja presença na África é massiva, é apontada como um dos motivos da transformação das políticas sexuais de vários países do continente no sentido de uma violenta radicalização das leis da época colonial que criminalizavam comportamentos homossexuais. Nesta direção, vão, por exemplo, os estudos de Kapya Kaoma (2009; 2012; 2014; 2016), pastor anglicano de Zâmbia, hoje vinculado à Diocese Episcopal de Massachusetts, que há vários anos, documenta como as guerras culturais americanas, ao redor da moral, da religião e dos costumes, vêm sendo implementadas em vários países do continente, em particular, por meio da ação de igrejas evangélicas ${ }^{3}$. Em um artigo anteriormente publicado, descrevemos detalhadamente os argumentos da pesquisa de Kaoma, que apontam para a expansão do conservadorismo nas igrejas evangélicas africanas, tradicionalmente mais progressistas no plano social, como uma estratégia da direita cristã norte-americana (Rea, 2020).

Com isso não queremos dizer que o fenômeno do pentecostalismo africano, em grande crescimento ao nível continental, seja apenas uma importação estadunidense. De fato, existem, no continente africano, igrejas pentecostais autóctones, como é bem documentado pelos estudos de Adriaan van Klinken e Ezra Chitando (2016) e de Kim Knibbe (2009), a propósito do pentecostalismo nigeriano. A partir de um estudo conduzido na Nigéria, na Holanda e na Inglaterra, Kim Knibbe documenta amplamente o desenvolvimento de poderosas "redes religiosas transnacionais nigerianas” (Knibbe, 2009, p. 36), como a Igreja Sunday Adelaje e, sobretudo, a Redeemed Christian Church of God que estão expandindo seu culto em direção à Europa e aos Estados Unidos. Consideramos, porém, que apesar da existência de um pentecostalismo autóctone africano, estas igrejas mantém uma agenda teológico-política parecida com a de igrejas pentecostais norte-americanas, como a pauta antigay (Klinken; Chitando, 2016) e o evangelho da prosperidade (Knibbe, 2009).

Na perspectiva de Kaoma, a reivindicação da não africanidade da homossexualidade e do caráter unicamente heterossexual do continente africano, que poderia ser confundida com uma demanda local e própria às diferentes culturas e valores africanos, parece ser recolocada em uma trama político-teológica mais complexa,
3 Conforme o próprio Kapya Kaoma relata no documentário God Loves Uganda, ele realizou uma pesquisa em Uganda, denunciando as relações entre o projeto de lei contra a homossexualidade e a direita cristã norte-americana.

Tendo-se colocado a favor dos direitos das minorias sexuais, teve que fugir de Uganda, sendo ameaçado de morte. Atualmente, vive e trabalha nos Estados Unidos, colaborando com a Faculdade de Teologia da Universidade de Boston. Kaoma é conhecido como defensor dos direitos humanos das minorias sexuais e, também, atua como pesquisador para Political Research Associates um thinktank progressista sediado no Massachusetts, pelo qual publicou as pesquisas Globalizing the Culture Wars. U.S. Conservatives, African Churches, and Homophobia (2009) e Colonizing African Values. How the U.S. Christian Right is Transforming Sexual Politics in Africa (2012). 
ampla e globalizada. A leitura dos textos de Kaoma nos ajuda, assim, a rever a ideia segundo a qual a afirmação de que a homossexualidade não é africana e não é compatível com as características culturais e religiosas africanas seria puramente e simplesmente derivada dos contextos locais. Ao contrário, lendo as análises de Kaoma, se pode concluir que esta tese é a expressão da globalização das guerras culturais estadunidenses e responde, em particular, a uma estratégia da direita cristã para impor sua agenda conservadora em matéria de costumes para além dos confins dos Estados Unidos. Assim, no artigo de 2012, Kaoma chega a afirmar que "a homofobia pode ela mesma ser desafiada como um produto do colonialismo" (Kaoma, 2012, p. 1). E, citando Marc Epprecht (2008), Kaoma continua explicando que os colonizadores europeus, que eram cristãos, reprimiram comportamentos sexuais não heteronormativos, comuns entre os povos africanos e considerados como contra a natureza.

Não concordamos, porém, plenamente com esta conclusão de Kaoma sobre o caráter totalmente estrangeiro e importado da homofobia no continente africano. Como já dissemos, não visamos a romantizar a África pré-colonial como se fosse um paraíso para as pessoas não heterossexuais ou um lugar sem homofobia. Sobre esse ponto, poder-se-ia mencionar as reflexões do filósofo camaronês, Achille Mbembe, quando evoca ao culto do falo nas antigas tradições pré-coloniais ou às tradições patriarcais, enquanto fundadas no recalque da homossexualidade (Mbembe, 2000). Em uma entrevista de 2012, Mbembe aponta para a existência do recalcado nas antigas sociedades africanas, onde relacionamentos sexuais entre homens existiam nas práticas cotidianas, nos rituais e funções de confraternização (Mbembe, 2012 apud Rea, 2018). Nesta direção, Thabo Msibi afirma que, apesar da existência de formas de desejo entre pessoas do mesmo sexo na África pré-colonial, a sexualidade procriadora era particularmente valorizada, dado que a "identidade sexual de um homem era construída em relação à reprodução" (Msibi, 2011, p. 64).

Não é nosso objetivo, nesse texto, apresentar uma reconstrução histórica e antropológica das sexualidades e dos desejos do mesmo sexo na África pré-colonial ${ }^{4}$. Trata-se, aqui, muito mais de problematizar e investigar um fenômeno atual, como o da homofobia em contextos africanos, que foi considerada, na leitura homonacionalista da mídia ocidental, como um marco típico das culturais locais, para mostrar que ela também tem raízes externas ao continente africano. Conforme escreve Kaoma em um texto de 2014, "a política sexual da África deveria ser entendida a partir da perspectiva das guerras culturais dos Estados Unidos, de um lado, e a partir das realidades sócio-políticas da África, do outro lado” (Kaoma, 2014, p. 2). Após os relatórios de 2009 e de 2012, Kaoma alarga sua leitura sobre a política sexual da África, incluindo a ideia de glocalização e a importância das realidades sociais e políticas locais. Também, ele destaca que não somente a retórica e a militância antigay, contra o aborto e os direitos sexuais são globalizadas e americanizadas, mas também a retórica e a militância em prol dos direitos humanos LGBT, do aborto e do feminismo.

Com a noção de glocalização, Kaoma pretende explicar as dinâmicas através
4 Muitos pesquisadores africanos e ocidentais têm apontado para a existência de formas de homoerotismo entre os povos africanos, antes da colonização europeia, e para o fato de que estas pessoas podiam ter graus variados de integração nas sociedades locais (MSIBI, 2011; Blessol, 2013; Muthien, 2013; Tamale, 2013; Epprecht, 2008; Pell Gaudio, 2009). Porém, isso não significa que não existissem, ao mesmo tempo, formas de rejeição ou de preconceito contra estas pessoas, conforme mostrado no estudo de Gustavo Gomes de Costa Santos e Matthew Waites (2019). Através de um estudo comparado entre Moçambique e Quênia, estes autores concluem que "não parece que toda a oposição aos comportamentos do mesmo sexo derive do colonialismo" (Santos; Waites, 2019, p. 318). 
das quais as estratégias da direita cristã estadunidense são reapropriadas e reelaboradas pelos contextos locais e utilizadas para finalidades políticas especificas em tais contextos. Deste modo, "através da glocalização, o cristianismo africano evangélico/pentecostal transforma e domestica táticas e ideologias conservadoras norte-americanas úteis para servir para finalidades políticas localmente definidas, ao passo em que aumenta sua visibilidade na política nacional” (Kaoma, 2016, p. 118). A introdução da noção de glocalização, por parte de Kaoma, nos parece fornecer uma resposta às críticas que diversos autores (Currier; Cruz, 2016; Gevisser, 2010; MIGUEL, 2019) têm endereçado aos seus relatórios de 2009 e 2012. Tais críticas apontavam essencialmente para o fato de que a tese de Kaoma retiraria a agência de líderes e populações locais, ao afirmar que esses adotam uma agenda anti-homossexualidade elaborada no exterior. Escreve o antropólogo Francisco Miguel:

Percebo então que a categoria "influência" é operada por ele quase sempre para lidar com o fluxo de valores EUA/África e raramente é usada no movimento inverso. De fato, o que se percebe quase sempre em suas declarações é um viés difusionista britânico que enxerga o fluxo de ideias e moralidades de uma perspectiva linear e unidirecional (Miguel, 2019, p. 20).

Pensamos, porém, que o fenômeno da globalização e da expansão das guerras culturais não elimina a especificidade dos contextos locais, dotados de agência e responsabilidade na forma com que estratégias práticas e conteúdos políticos são apropriados, reivindicados e "domesticados" pelos diferentes atores locais. Estes últimos estão longe de se colocar de forma passiva em relação aos discursos da direita cristã norte-americana, mas "formulam as suas posições antigay utilizando discursos e assuntos culturais específicos que não somente têm ressonância com um amplo público (...), mas que podem também ajudar e servir seus próprios interesses e fins políticos" (Oliver, 2013, p. 85).

As análises de Kaoma documentam amplamente estas táticas de penetração do conservadorismo cristão estadunidense em vários países africanos ${ }^{5}$, que se disfarça de luta anticolonial, enquanto representa, ao contrário, "uma campanha de conservadores ocidentais que estão fornecendo financiamento às igrejas africanas para usá-las, por procuração ( proxy force), em sua guerra cultural nos EUA" (Kaoma, 2009, p. 5). O pastor zambiano documenta como os conservadores religiosos e políticos estadunidenses e as lideranças de igrejas da Renovação conseguiram o apoio de líderes políticos e religiosos africanos, levantando a bandeira da homofobia e do ódio contra as minorias sexuais identificadas como incompatíveis com os valores africanos e como portadoras da ocidentalização e do neocolonialismo. Desta forma, a direita cristã estadunidense conseguiu alavancar boa parte do cristianismo na África e se passar por defensora de valores tradicionais africanos e afrocentrados, dos quais a homossexualidade estaria excluída.

A este propósito, gostaríamos de colocar, porém, uma ressalva. Não se trata aqui de considerar o cristianismo africano, particularmente, o de matriz evangé-
5 O relatório de Kaoma, de 2009, analisa os casos de Uganda, Nigéria e Quênia, enquanto no relatório de 2012, o autor estende a sua análise também para Malawí, Zimbabué, Libéria e Zâmbia. 
lica, como uniforme, homogêneo e unicamente inspirado nas visões político-teológicas da direita cristã estadunidense. Como mostra Adriaan van Klinken (2017), existem correntes de cristãos progressistas, ligadas às comunidades afro-americanas, ativas no continente africano e portadoras de uma agenda e de um discurso inclusivos e a favor das populações LGBTI. O estudo de van Klinken menciona o grupo TFAM (The Fellowship of Affirming Ministries), ativo na cidade de Nairóbi (Quênia).

No contexto internacional da discussão sobre a criminalização das minorias sexuais, o caso mais conhecido é o de Uganda, que tem sido amplamente espectacularizado pela mídia ocidental (Mwykia, 2013; Tamale, 2014), durante as duas últimas décadas. $\mathrm{O}$ ano de 2009 foi crucial no recrudescimento das leis contra a homossexualidade, herdadas do Código Penal Colonial britânico. Em outubro daquele ano, o deputado David Bahati submete um projeto de lei ao Parlamento ugandense que reforça as penas para os atos sexuais entre pessoas do mesmo sexo. Alguns meses antes, o militante evangélico norte-americano de direita e revisionista do Holocausto, Scott Liveley, tinha organizado um seminário junto à associação evangélica Family Life Network, para defender os supostos valores morais da família ugandense e contra a ameaça da homossexualidade (Kaoma, 2009).

Um violento debate se instala envolvendo discursos de ódio, disparo de notícias falsas, como as que ligavam o movimento homossexual com o nazismo ou com uma conspiração internacional voltada para recrutar e corromper crianças, e o outing de dissidentes sexuais por parte da mídia (Mwykia, 2013), enquanto em 2011, o militante gay e professor David Kato, era assassinado. Em 2012, a associação Sexual Minorities Uganda denuncia o caráter estrangeiro da pauta antigay e das discriminações e violências por ela suscitadas no país e aponta para a responsabilidade de evangélicos americanos como Scott Lively (Kaoma, 2012). No início de 2014, uma versão emendada do projeto de Lei é promulgada pelo presidente Yoweri Museveni, mas retirada alguns meses depois. A Corte Constitucional de Uganda declarou a inconstitucionalidade desta lei, alegando a falta de quórum no momento da votação. Porém, apesar da lei ter sido abandonada, o grau de violência contra a população LGBTIQ permanece muito alto e os grupos conservadores continuam impulsionando a retomada da lei. Como escrevem Stella Nyanzi e Andrew Karamagi, "os conservadores estrangeiros ocidentais, particularmente, os direitistas cristãos norte-americanos, catalisaram ativamente a recriminalização da homossexualidade aumentando o grau da sua desaprovação sociocultural na sociedade ugandense” (2015, p. 12).

\section{A politização da sexualidade em contextos africanos}

Como escreve Marcia Oliver, a maioria dos estudos sobre o "ativismo transnacional" (2013, p. 84) e sobre as minorias sexuais africanas não tem ainda explorado suficientemente as influências do conservadorismo cristão e da direita norte-americana na politização da sexualidade em vários países africanos. Inspirados na crítica Queer of Color, estes estudos apontaram, mais frequentemente, para as am- 
biguidades do ativismo pró-gay e em defesa dos direitos humanos, financiado por ONGs e associações LGBT do Norte global e animado por atitudes salvacionistas e paternalistas, ao enxergar as minorias sexuais na África e em outros lugares do Sul global como desempoderadas e necessitadas das ajudas que ativistas LGBT ocidentais, supostamente mais experientes e capazes, poderiam lhes oferecer, a fim de enfrentar o fenômeno particularmente violento da "homofobia africana". Estes estudos pretendem, assim, desvendar o caráter neoimperialista e neocolonial de tais intervenções de ONGs e militantes ocidentais em países africanos e afirmam que estes atores exportam não somente uma visão branca e ocidental da homossexualidade, mas também o modelo capitalista neoliberal e uma gestão desigual dos recursos e das ajudas humanitárias. Em várias contribuições já publicadas, temos atentado para a importância destas contribuições e reportado às críticas sinalizadas pelxs Queer of Color e pelxs Queer Africanxs ao homonacionalismo, expresso por boa parte do ativismo LGBT transnacional, assim como ao mito de uma África terrivelmente homofóbica (Rea, Amancio, 2018; Rea, 2018; Rea, 2017).

Antes de continuar o fio de nossa discussão, compreendemos que seja necessário retomar brevemente tais análises elaboradas pela Crítica Queer of Color e pela Crítica Queer Africana. Esta breve digressão permitirá situar mais solidamente o nosso referencial teórico e "escurecer" nosso posicionamento em relação aos argumentos de Kaoma e aos discursos dominantes sobre a dissidência sexual em contextos africanos. Partimos das análises de Francisco Miguel, na introdução à sua tese doutoral, onde o autor se questiona sobre o porquê de "tamanha adesão ao discurso de ódio contra a homossexualidade em África" (Miguel, 2019, p. 20). Mencionando o relatório de Kaoma de 2009, Miguel considera insuficientes os argumentos do pastor zambiano para definir uma resposta ao fenômeno da "massificação da homofobia no continente" (idem). Quanto ao discurso da exogenia da homossexualidade na África, o autor considera que este deva ser levado a sério e cita o argumento da discrição e do silêncio que encobriria as práticas sexuais do mesmo sexo, no continente. Assim, afirma o antropólogo brasileiro, "vários pesquisadores em e de África veem [sic] apontando recorrentemente que silêncio e discrição são duas categorias que parecem ser centrais quando o assunto é (homo) sexualidade no continente” (Miguel, 2019, p. 26). Dentre estes pesquisadores, continua Miguel, tem quem vê no silêncio uma "estratégia de escape à opressão" (idem) e quem vê nele uma "norma e não (...) necessariamente algo opressivo" (idem). Por sua parte, Miguel sugere que "este silêncio parece ser fruto de decisões civilizacionais e históricas que alocam suas práticas homoeróticas na intimidade, mas que estão sujeitas à transformação" (Miguel, 2019, p. 27).

Neste ponto, consideramos importante passar pelas reflexões da Crítica Queer of Color, quando esta contesta o caráter eurocêntrico e neoimperialista da agenda global LGBT, elaborada pelo que Joseph Massad define como a "Internacional Gay" (2007). Nas culturas africanas e não ocidentais é comum que um certo silêncio e discrição sejam mantidos sobre as sexualidades não heteronormativas e que práticas como o coming out e a afirmação da visibilidade não sejam consideradas como indispensáveis, assim como acontece no mundo ocidental. Estas epistemologias/ 
políticas não ocidentais da sexualidade implicam uma maior fluidez que perpassa a rígida distinção entre homo e heterossexualidade, própria à cultura ocidental e implicam outras "configurações sociais e sexuais do desejo" (Massad, 2007, p. 187). A postura do silêncio deve, portanto, ser considerada como uma epistemologia/ política da sexualidade diferente da nossa ${ }^{6}$.

Puxar na direção de uma visibilidade a qualquer preço, calcada no modelo euro-americano sem levar em conta as especificidades culturais locais equivale a correr o risco de impor uma concepção particular da identidade, mas sobretudo de colocar em perigo pessoas que têm relacionamentos com parceiros do mesmo sexo e que negociam diferentemente sua relação com estas práticas (Cervulle; Rees-Roberts, 2010, p. 37).

Retomando as ideias de Massad, Sokari Ekine conecta a ação da Internacional Gay com a questão da visibilidade gay e aponta para a "substituição do silêncio por um engajamento ativo e assertivo perante o Estado" (Ekine, 2013, p. 85). Tal engajamento ativo seria, segundo a autora, efeito do internacionalismo gay:

Ao lado do aumento da visibilidade e do ativismo que a acompanha, houve um aumento da presença e da intervenção daquilo que Massad chama de Internacional Gay - ONGs e ativistas LGBT, brancos e ocidentais, animados por um interesse quase obsessivo de encontrar a homofobia no Sul global (idem).

A posição de Sokari Ekine, aqui relatada, nos parece encarnar a crítica queer of color à ideia de "condição gay compartilhada" (idem), que a agenda internacional estaria exportando para contextos culturais nos quais desejos e relacionamentos homoeróticos se expressam em uma diferente epistemologia da sexualidade. Massad tem discutido as consequências paradoxais às quais conduz a atitude missionária e salvacionista da Internacional Gay ao tentar libertar os dissidentes sexuais no mundo "da opressão sob a qual supostamente eles vivem, transformando-os de praticantes do relacionamento do mesmo sexo em sujeitos que se identificam como 'homossexuais' e como 'gays"' (Massad, 2007, p. 162).

Neste sentido, consideramos problemática qualquer aceitação acrítica da ideia segundo a qual, a partir da modernidade ocidental, estaria em ato uma transformação definitiva das conformações africanas da intimidade e do desejo. Com certeza, a África é um continente complexo, híbrido e plural, como aponta a noção de afropolitanismo de Achille Mbembe (2014) ${ }^{7}$. Porém, consideramos que o caminho da democracia sexual (FASSIN, 2008) moderna não se dá sem paradoxos e contradições e que o conflito e as tensões que a atravessam marcam diferentes eixos de poder. Ou seja, na leitura descolonial que propomos, a transição para a suposta modernidade encarnada pela democracia sexual está atravessada pela "matriz do poder colonial" (BAKSHI, JIVRAJ, POSOCCO, 2016, p. 2) com seu enredo interseccional de relações de dominação, que conduz à desvalorização e à
6 Esta prática do silêncio não parece, porém, implicar necessariamente o silenciamento, nem o mito da heterossexualidade obrigatória, que apaga a fluidez das sexualidades locais e das formas endógenas da dissidência sexual.

7 É interessante destacar que, para Mbembe, o fenômeno da "circulação dos mundos" que caracteriza a noção de afropolitanismo não é uma marca da modernidade nem da colonização. Assim, escreve o filósofo camaronês, "existe uma modernidade africana pré-colonial que ainda não foi alvo de 
subordinação de outras narrativas da dissidência sexual.

Várixs ativistas e acadêmicxs africanxs têm destacado que o "modelo da democracia sexual" (Cervulle; Rees-Roberts, 2010, p. 40), defendido pelos "global gays", traz consequências negativas para os movimentos locais. Ayo Coly resume bem estas inquietações, quando formula a hipótese da relação entre a ação do internacionalismo gay e o aumento da homofobia de Estado. Escreve a autora, a este propósito:

O assim chamado internacionalismo gay - a imposição de quadros e agendas sexuais ocidentais universalizados - e as ameaças de sanções por parte dos doadores contra Estados africanos homofóbicos também facilitam mais do que nunca o trabalho da homofobia de Estado em África. A homofobia de Estado está agora em condição de se apresentar como uma salvação para a população e como a guardiã da integridade moral da nação (Coly, 2013, p. 29).

Constatamos que, nos relatórios de 2009 e de 2012, Kaoma não trabalhou esta vertente do neoimperialismo ocidental, apontando unicamente para a agenda transnacional evangélica e da direita cristã estadunidense. Porém, como já sinalizamos, em textos mais recentes, Kaoma tem alargado suas reflexões sobre o caráter global dos discursos dos direitos humanos LGBT na África, enquanto também portadores de agendas e interesses estrangeiros e ocidentais. De fato, considera Kaoma, tanto os grupos pró-gays como os grupos antigays seriam influenciados por interesses estrangeiros e por uma agenda internacional. Como constata Kaoma,

[os] defensores dos direitos gay (...) são igualmente ajudados por estruturas globais de governança - as Nações Unidas e as organizações ocidentais dos direitos humanos. Estes grupos focam em ganhar "solidariedade global", como uma outra maneira de fazer avançar os direitos sexuais na África. Eles também exportam modelos ocidentais do ativismo dos direitos sexuais (Kaoma, 2014, p. 3).

O interesse da posição de Kaoma está, para nós, na análise das atuais políticas sexuais na África e no Sul global, como expressão dos principais eixos de poder que atravessam o mundo contemporâneo, como o neoimperialismo, as heranças das relações coloniais e as desigualdades entre Norte e Sul globais. Para além disso, suas análises nos ajudam a compreender os desdobramentos deste neoimperialismo, cujas manifestações atravessam os dois polos opostos das guerras culturais. consideração na criatividade contemporânea" (Mbembe, 2014, p. 183). Consideração esta que poderia perturbar o imaginário homonacionalista e sua fronteira supostamente marcada entre modernidade sexual ocidental e pré-modernidade dos mundos não ocidentais. 


\section{Guerras culturais e direita cristã nos Estados Unidos: análise do conceito}

Neste texto, queremos evidenciar a influência do cristianismo conservador e da direita cristã estadunidense, como uma vertente do neoimperialismo, cuja presença é marcante nos discursos e nas medidas anti-homossexualidade, que vários líderes africanos têm recentemente adotado. As contribuições de Kaoma sobre a globalização das guerras culturais e a exportação da ideologia pró-família e da agenda antigay da direita cristã norte-americana são questões que merecem mais atenção para a compreensão dos acontecimentos ao redor da politização da sexualidade no continente africano.

A ideia do caráter intrinsecamente heterossexual da sexualidade africana tem uma história longa e está enraizada nos discursos coloniais que pretendem regular o gênero e as relações sexuais e familiares dos povos colonizados, moldando-os segundo o modelo da rígida moral cristã vitoriana. Como lembra a feminista ugandense, Sylvia Tamale, em comparação com "as normas sexuais altamente conservadoras da Europa, as sexualidades dos africanos, que eram relativamente desenfreadas (unrestrained), colocavam grandes desafios para as mentes vitorianas dos primeiros exploradores” (Tamale, 2011, p. 15). A penalização das relações entre pessoas do mesmo sexo foi assim implementada como parte do Código Penal colonial e constituía as chamadas leis antissodomia, vigentes nas colônias britânicas (Gevisser, 2010b). Como afirma ainda Sylvia Tamale, as sexualidades dos africanos, particularmente das mulheres, eram apresentadas, pelos missionários e exploradores brancos, como primitivas, exóticas e bestiais, segundo uma leitura manifestamente etnocêntrica e racista (TAMALE, 2011). Nesta linha, Monica Oliver destaca que se a ideologia colonial se baseava na naturalização dos comportamentos e dos costumes dos povos africanos, ela não conseguia, portanto, enxergar para eles uma outra forma de sexualidade que não fosse a heterossexual e reprodutora. Assim, ao "descrever os negros como a essência da natureza, os colonizadores não podiam imaginar que a sexualidade africana fosse diferente da heterossexual e procriadora" (Oliver, 2013, p. 92). E essa ideia de uma sexualidade naturalizada e reduzida ao seu papel reprodutor permeia os valores pró-família e a agenda anti-homossexualidade dos conservadores cristãos nos Estados Unidos e ao redor do mundo. E aqui é interessante notar, desde agora, que esta estratégia de naturalização da sexualidade nos discursos da direita cristã serve, ao mesmo tempo, para construir homossexualidade e raça como categorias opostas e inconciliáveis, assim fortalecendo o mito colonial segundo o qual a negritude e a africanidade seriam incompatíveis com a homossexualidade, sendo forjadas pela heterossexualidade natural (Oliver, 2013). Voltaremos mais tarde sobre este tema, pois ele define o enredo de políticas raciais e sexuais da direita cristã norte-americana.

Precisamos, então, partir do conceito de guerras culturais e de seu uso no campo conservador norte-americano, no qual o conceito se consolidou a partir dos anos 1990 para indicar as divisões socioculturais e políticas da sociedade norte-americana (HARTMAN, 2019). Certo é que este conceito está longe de ter 
a unanimidade entre os pesquisadores, assim como a ideia de que a sociedade americana seria realmente polarizada e profundamente dividida. Porém, como destaca o estudioso canadense Frédérick Gagnon, o conceito de guerras culturais tem se tornado, nos Estados Unidos, além de um poderoso instrumento midiático, uma estratégia para "promover as ideias da direita cristã" (Gagnon, 2009, p. 403) e suas cruzadas em prol da moral tradicional e da religião. Neste sentido, ele merece atenção.

O militante da direita evangélica Scott Lively, que participou do seminário em Kampala no início de 2009, escreve, na introdução do seu livro Redeeming the Rainbow, que "a igreja deve acordar para a realidade de que a assim chamada 'guerra cultural' é, mais do que outra coisa, uma disputa entre as opostas e contraditórias filosofias do ativismo homossexual e do cristianismo" (Lively, 2009, p. v). Este trecho é particularmente emblemático, e expressa a visão da direita cristã, ao situar as guerras culturais diretamente no coração das questões de gênero e sexualidade e ao fazer da reivindicação ligada aos direitos das minorias sexuais a principal inimiga do cristianismo. Lively parte da afirmação segundo a qual estaria em ato uma confrontação entre cristãos e homossexuais pelo controle da cultura e que o ativismo homossexual estaria almejando a "capitulação da cultura para a sua agenda" (Lively, 2009, p. iv), representando uma ameaça para a civilização ocidental e para os valores da moral sexual cristã e da família heterossexual sobre os quais tal civilização estaria edificada. Como escreve Lively, o "objetivo gay para a sociedade é substituir a moral sexual judaico-cristã (o casamento monogâmico heterossexual e a família natural) por um sistema moral alternativo que abraça a liberdade sexual” (Lively, 2009, p. v). De fato, a homossexualidade e, particularmente, o ativismo em prol dos direitos sexuais são enxergados por Lively como o maior perigo para a civilização cristã, nos Estados Unidos e para o resto do mundo. Desta forma, as guerras culturais se derramam em várias direções e implicam diversos conflitos, mas o enfrentamento da causa homossexual permanece o fundamental desafio para os cristãos pró-família. "A ética gay - escreve Lively no mesmo livro - é uma hidra cujas múltiplas cabeças são os direitos gays, os casamentos em série, o aborto, a pornografia e outras iniquidades sociais ligadas ao sexo. Nossa tarefa, como pessoas que tentam restaurar a primazia da família é de matar a serpente ideológica do libertinismo sexual, mesmo continuando a enfrentar cada uma de suas cabeças letais" (Lively, 2009, p. 61).

Em seu livro The Antigay Agenda (1997), que estuda a direita cristã estadunidense, a acadêmica Didi Herman informa sobre a existência de uma vasta literatura antigay (livros, palestras, workshops e seminários) produzida por esta vertente político-teológica e explica que a pauta antigay foi se tornando uma prioridade a partir dos anos 1980 e 1990, em oposição à visibilidade que o movimento gay ia assumindo nos Estados Unidos. Este movimento era considerado como uma ameaça poderosa cuja agenda levaria à destruição da sociedade, da educação e da família americanas. A concepção da condição homossexual apresentada pela direita cristã baseia-se na ideia da homossexualidade como pecado e como um "comportamento escolhido, e não como um caráter genético ou psicológico imutável” (Herman, 
1997, posição 673). A direita cristã apresenta uma profunda fixação com o comportamento sexual dos homens gays, sempre representado como promíscuo, perverso e doentio. "Os homens gays - relata Herman - são acusados de brincar com urina e excrementos, de ter uma incidência enormemente desproporcionada de doenças sexualmente transmissíveis e de serem, em geral, devastados fisicamente e psicologicamente" (posição 744). Não insistiríamos tanto em apresentar estas fixações da direita cristã sobre os chamados comportamentos "sodomitas" e a acusação de recrutar, corromper e destruir crianças, dirigidas contra os gays, se elas não constituíssem uma peça importante dos discursos homofóbicos no continente africano, como é bem relatado no documentário do diretor afro-americano Roger Ross Williams, God Loves Uganda. O filme mostra um acalorado discurso do pastor ugandense Martin Ssempa, representante dos missionários evangélicos americanos no país e líder, junto com o parlamentar David Bahati, na promoção do projeto de lei anti-homossexualidade, que após descrever o que supostamente seria o sexo gay, declara para a multidão: "Como africanos, queremos perguntar para o presidente Obama se é isso o que ele entende levar para a África e trazer para a raça humana: comer os excrementos de outros homens?" (trecho do documentário God Loves Uganda). Este trecho mostra abertamente que a retórica antigay em Uganda e em muitos países africanos é a exportação de um imaginário e de discursos amplamente consolidados no seio da política sexual da direita cristã estadunidense. $\mathrm{E}$ seria impossível não relembrar o caráter fascista destes discursos que, como muito bem afirma Didi Herman, foram em outros tempos usados para estigmatizar os judeus e outros grupos marginalizados e criminalizados.

Estes temas da doença e da sedução são fortemente evocativos de antigos discursos antissemitas. Os judeus foram historicamente associados com a doença, a sujeira, a degeneração urbana e o roubo de crianças (veja Gilman, 1991; Mosse, 1985) (Herman, 1997, posição 770) ${ }^{8}$.

Embora estejam centradas nas questões sexuais e de gênero, como os direitos das minorias sexuais, o aborto, a família, a pornografia, a igualdade de gênero ou a educação sexual, as guerras culturais investem outros aspectos no campo dos costumes, da moral, dos comportamentos e das crenças, como o multiculturalismo, a integração, as questões raciais, o lugar da religião, particularmente a cristã, e seus possíveis conflitos com a ciência, o lugar do cânone ocidental no estudo das Humanidades e no ensino superior. A lógica das guerras culturais consiste em desviar a discussão política de assuntos mais técnicos, como a política econômica, institucional ou o sistema político-jurídico, para recolocar a polarização no âmbito de questões morais, de costumes e de crenças. Tal estratégia consegue, mais facilmente, mobilizar amplos setores da sociedade, que se sentem diretamente investidos pelas escolhas culturais assim realizadas. É nesse sentido que o historiador norte-americano Andrew Hartman (2019) fala das guerras culturais como guerras pela alma da América, em seu livro The Wars for the Soul of America, no qual fornece uma história detalhada das guerras culturais nos Estados Unidos,
8 Didi Herman (1997) mostra as visões contrastantes da direita cristã estadunidense sobre o povo judeu e destaca sua oscilação entre um posicionamento tradicionalmente antissemita e a visão escatológica do dispensacionalismo pré-milenial, que atribui importância ao Estado de Israel e ao retorno dos judeus para Palestina no processo escatológico do fim dos tempos. Desta forma, "o apoio entusiástico da direita cristã a Israel (...), em particular, na luz de seu antissemitismo permanente, não fariam sentido sem uma compreensão do papel que o povo judeu deve desenvolver no fim do mundo" (Herman, 1997: posição 250). O termo posição se refere à versão kindle, que não menciona o número de página. 
apresentando as suas diversas frentes. O conflito cultural foi um elemento constante na história norte-americana, conforme aponta Andrew Hartman, mas se intensificou radicalmente a partir dos anos 1960 e ao longo das décadas seguintes, em decorrência da ação dos movimentos sociais mobilizados ao redor de grupos sociais que até então tinham sido excluídos da definição hegemônica e normativa do que é a América e de quem são os americanos. E Hartman continua explicando que as guerras culturais marcam justamente esta linha de separação entre os apoiadores de tais mudanças e transformações, e os que aspiram por uma volta ao passado e por uma hegemonia da América normativa, branca, cristã, moralmente conservadora, burguesa, masculina e heterossexual. Para os grupos que representam a velha América, as transformações sociais e culturais iniciadas nos anos 1960 representam uma profunda ameaça. "As mobilizações políticas radicais dos anos sessenta - direitos civis, o Black e Chicano Power, o feminismo, a libertação gay, o movimento antiguerra, o avanço legal para a secularização - desestabilizaram a América que milhões de pessoas conheciam. Foi somente depois dos anos 1960 que muitos, especialmente os conservadores, reconhecem a ameaça para aquela que foi então a sua grande nação" (Hartman, 2019, posição 108). Entre os valores, as convicções e ideologias desta "grande nação" americana, que Hartman chama de "América normativa" (2019, posição 121), estão as estritas normas sexuais, de gênero e raciais, compartilhadas pelas classes médias e baseadas na ideia do casamento heterossexual, em uma sexualidade rigorosamente procriadora e em papéis de gênero bem definidos, que asseguram ao homem a condição de provedor e à mulher a de dona de casa e de cuidadora das crianças, na valorização do legado cristão da nação e na suposta superioridade da branquitude (Hartman, 2019).

Se, como destaca ainda Hartman, os progressistas têm ganhado no plano das transformações culturais e de costumes, os conservadores continuam a manter grande força no plano político e eleitoral, através do poder da direita cristã e seus setores evangélicos que ganharam alcance durante o governo de Ronald Reagan e, particularmente, no de George W. Bush.

Através de seu engajamento nas guerras culturais e de sua atividade antigay, a direita cristã representa muito mais um conservadorismo social do que econômico (HERMAN, 1997), mesmo se, através do chamado evangelho da prosperidade, ela adota uma visão teológico-econômica perfeitamente compatível com a agenda capitalista neoliberal, quanto à redução do papel do Estado na diminuição das desigualdades sociais. Apesar de outras pautas estarem presentes na definição do que chamamos de direita cristã, ela se caracteriza, mais marcadamente, por sua defesa da família tradicional heterossexual e pela sua aversão radical aos direitos LGBT e à libertação sexual, que supostamente ameaçam a estrutura familiar. Os posicionamentos de Scott Lively, que discutimos precedentemente, mostram este enredo na visão da direita cristã.

Didi Herman define a direita cristã estadunidense como um movimento "principalmente protestante" (Herman, 1997, posição 114), embora inclua associações, grupos e indivíduos ligados à igreja católica ${ }^{9}$. A autora explica que a pauta e a atividade antigay são puxadas pela matriz cristã do movimento e que, apesar dos
9 No texto Colonizing the African Values, Kapya Kaoma menciona a associação católica Human Life International (HLI) entre os principais grupos operativos na África "dedicados a 
conservadores de outras religiões poderem pontualmente se associar à direita cristã em algumas de suas batalhas, "em relação às políticas antigay, não existe uma direita religiosa em geral. Nos Estados Unidos, a oposição aos direitos gays é guiada, impulsionada e inspirada pelos cristãos e pela fé cristã” (posição 125). Do ponto de vista teológico, a direita cristã se caracteriza, segundo essa autora, a partir de duas fundamentais crenças, que são "a infalibilidade bíblica” - que parte da interpretação literal das Escrituras e rejeita qualquer leitura crítica e em perspectiva histórica das mesmas - e a ideia escatológica do "dispensacionalismo pre-milenial” (Herman, 1997, posição 136), característico do protestantismo evangélico. A leitura de Kaoma nos permite, porém, acrescentar a este marco teológico, o evangelho da prosperidade, que "afirma que a simples fé em Jesus Cristo trará riqueza e bem-estar" (Kaoma, 2012, p. vii) e a teologia do domínio, segundo a qual os cristãos devem dominar em todos os campos da sociedade, incluindo na empresa, na educação, na mídia e no governo (Kaoma, 2012). Estes pilares teológicos do protestantismo evangélico, que marcam a direita cristã nos Estados Unidos, estão amplamente difundidos no continente africano.

Um ponto ainda para analisar é o da política racial da direita cristã estadunidense, ou mais precisamente, as intersecções entre política sexual e política racial. Didi Herman afirma que a direita cristã representa o heteropatriarcado branco e as classes abastadas dos Estados Unidos ${ }^{10}$. Seguindo as reflexões de Herman, Marcia Oliver tem insistido em apontar para a estratégia adotada pela direita cristã, voltada para minar e impedir qualquer unificação entre os movimentos antirracistas e os movimentos LGBT. A autora destaca que, ao longo dos anos 1990, grupos da direita cristã, tradicionalmente branca e racista, tentaram defender "a reconciliação racial (...) no esforço de ganhar o apoio dos afro-americanos para suas agendas morais e políticas” (Oliver, 2013, p. 93). Nesta linha deve ser lido o ativismo internacional destes grupos e sua expansão em direção à África e ao Sul global. Surfando sobre o mito de uma sociedade pós-racial ${ }^{11}$, a direita cristã colocou os valores da família - na verdade, o modelo familiar branco, europeu e burguês - como cristãos e universais, e gastou, assim, suas energias em aprofundar a fratura entre negritude e africanidade de um lado, e condição LGBT do outro. "O ativismo global da direita cristã - escreve ainda Oliver - pode ser visto, desta forma, como uma extensão desta mudança na estratégia política, com os 'valores familiares' cristãos, universais e pós-raciais, que servem para mitigar as heranças raciais e coloniais da família natural (branca)" (Oliver, 2013, p. 93). É nessa linha que a tese da não-imutabilidade da homossexualidade e sua identificação como uma escolha sexual e não como um caráter inato se torna uma peça fundamental para justificar a suposta oposição e a irredutibilidade da condição homossexual em relação à condição racial. Ou seja, os direitos LGBT são rejeitados em nome do caráter não inato e mutável da homossexualidade, enquanto os direitos dos negros passariam a ser defendidos por ser a cor da pele uma dimensão natural, inata e não mutável do ser humano que, como tal, não pode ser imputada como culpa ou erro moral.

Forçando a ideia da oposição entre as minorias sexuais e as minorias raciais, promover a sua visão do mundo ligada à direita cristã" (Kaoma, 2012, p. vi).

10 Embora existam personalidades e organizações conservadoras cristãs entre a população racializada nos Estados Unidos, segundo Herman, são poucas "as pessoas de cor e as organizações não brancas [que] podem ser encontradas à frente do movimento antigay nacional" (posição 118).

11 Para uma discussão mais detalhada sobre as noções de pós-racial e pós-racialidade, reenviamos para Bacchetta, Maira; Winant, 2019. Atrás da pretensão de ter superado a dominação e discriminação raciais, a ideia de sociedade pós-racial "trabalha para legitimar políticas racistas, para suprimir ou enfraquecer as críticas ao racismo e para minar os movimentos que enfrentam as permanentes opressão, repressão, exploração e desigualdade raciais e coloniais" (Bacchetta; Maira; Winant, 2019, p. 11). 
a direita cristã considera que as primeiras não seriam uma verdadeira minoria discriminada e marginalizada, mas um grupo de impostores que não merecem os direitos que reivindicam. A direita cristã adotou mais recentemente o discurso segundo o qual os homossexuais, individualmente e socialmente, constituiriam uma elite rica e poderosa, ávida por mais direitos e privilégios, que visa a se fazer passar por merecedora de proteções específicas (Herman, 1997). Este argumento sobrevive mais ou menos pacificamente ao lado do mais enraizado tema da mutabilidade da sexualidade gay (Herman, 1997), e é defendido, hoje, por muitos adversários dos direitos LGBTI no continente africano, onde as minorias sexuais são, em muitos casos, acusadas de serem a expressão de elites econômicas e culturais (Ossome, 2013) ${ }^{12}$. Porém, nos Estados Unidos, como no caso da África, o discurso dos homossexuais como não merecedores de direitos em comparação com os grupos racializados colide, mais uma vez, com o tradicional racismo da direita cristã estadunidense e sua aversão ao Estado de bem-estar. Didi Herman aponta que tais discursos

levantam numerosas dificuldades para esta política racial, particularmente suas dimensões antiestado. Ao representar as lésbicas e os gays como não merecedores [de direitos], porque estariam longe de serem tão pobres e sub-representados, como os que realmente são desfavorecidos, pareceria que a direita cristã subentende que estas pessoas realmente desfavorecidas merecem os direitos especiais (Herman, 1997, posição 1239).

A análise de Herman é interessante e revela o paradoxo de tal posicionamento, pois a história da direita cristã está marcada pela oposição às políticas de bem-estar, que são acusadas de perpetuarem a dependência dos grupos beneficiados, em particular, dos grupos racializados. Ou seja, como a direita econômica, a direita cristã caracteriza-se pela histórica rejeição neoliberal das políticas de intervenção do Estado para corrigir as desigualdades sociais e apoiar as classes e os grupos mais desfavorecidos. E precisamos, aqui, destacar que esta oposição ao Estado de bem-estar social está, em boa parte, fundamentada no mito do matriarcado negro, que culpa as comunidades negras e, particularmente, suas mulheres de serem aproveitadoras e as estigmatiza enquanto "rainhas do welfare". A filósofa e feminista francesa Elsa Dorlin (2010) explica:

As mulheres negras são assim comumente consideradas responsáveis pela ruína da nação. Os discursos neoliberais, opostos a qualquer política social, popularizam a figura da "rainha do welfare" (...), quase exclusivamente representada com os traços de uma mulher negra pobre. Acusadas de se aproveitarem da generosidade federal, as mulheres negras são vistas como mulheres dominadoras, castradoras, que afastam seus homens, enquanto levam seus filhos a viverem em lares desordenados, desestruturados, pois mantidos por mulheres (Dorlin, 2010, p. 75).
12 No caso dos Camarões, Patrick Awondo documenta um escândalo midiático e jurídico, acontecido em 2006, que implicou as elites políticas e econômicas do país. Neste caso, parece se definir uma relação entre homossexualidade e poder, embora o próprio Awondo reconheça que, na onda da caça aos homossexuais que disso resultou, muitos jovens das classes menos abastadas foram também visados (Awondo, Geschiere, Reid, 2013). Awondo (2019, capítulo 2) também aprofunda as relações entre homossexualidade, poder e dimensão do oculto, com base no pânico moral orquestrado pela mídia e veiculado pela população. 
Não podemos entrar aqui nestas análises, que demandariam o desenvolvimento de um outro texto, mas queremos lembrar que, de Patricia Hill Collins (2019) a bell hooks (2019) e Angela Davis (2016), muitas feministas negras têm amplamente mostrado o enredo de sexismo e de racismo contido nesses discursos e denunciado como a defesa dos valores familiares e da família tradicional têm frequentemente se acompanhado da patologização das comunidades afrodescendentes.

Como vimos, através da análise dos textos de Didi Herman e Marcia Oliver, uma das principais estratégias da direita cristã nos Estados Unidos tem sido a da produção de fraturas e separações entre as minorias sexuais e de gênero, de um lado, e as minorias racializadas do outro, ao impedir qualquer solidariedade entre as comunidades afrodescendentes e a comunidade LGBT, e ao retratar estas últimas como essencialmente brancas e suas pautas como uma ameaça para os direitos civis das populações negras. Esta mesma política de divisão é aplicada no continente africano, onde o imperialismo religioso é disfarçado e encoberto através da ideia, incessantemente reiterada, da não africanidade da homossexualidade ou de pautas ligadas à igualdade de gênero.

\section{Conclusão}

Este texto procurou discutir a difusão do fundamentalismo evangélico em contextos africanos - particularmente de países de ex-colonização britânica como sendo expressão de guerras culturais, ideológicas e políticas promovidas por instituições e organizações vinculadas à direita cristã estadunidense. Esta vertente do neoimperialismo tem repercutido de forma violenta sobre a condição das minorias sexuais africanas, através do fortalecimento de leis anti-homossexualidade que vários governos tentaram implementar em diferentes países do continente. Consideramos que estas análises, que desenvolvemos na base dos estudos realizados por Kapya Kaoma, representam uma peça importante na desconstrução da lógica do suposto "excepcionalismo" norte-americano em matéria de gênero, sexualidade e democracia.

Nessa linha, tentamos, também, questionar a ideia segundo a qual o mundo ocidental exportaria prioritariamente a agenda dos direitos LGBT, enquanto o Sul global e o continente africano, em particular, estariam uniformemente prisioneiros de uma homofobia obsessiva e nefasta. Mostramos, ao contrário, que o mundo ocidental e os Estados Unidos, que comumente o representam, também, exportam homofobia e intolerância contra a dissidência sexual e de gênero.

Concluímos, destacando mais uma vez a importância da tese de Kapya Kaoma, na medida em que ela discute o fator do neoimperialismo estadunidense como uma das motivações principais que permitiram a difusão da homofobia de Estado, na África. De fato, pensamos que o que aconteceu e ainda acontece em vários dos países africanos, aqui mencionados, poderia estar por acontecer, hoje, na América Latina. Na hora em que escrevemos estas linhas, se desenha a pergunta de se a atualidade da política brasileira, com o crescimento do autoritarismo e da perseguição às questões de gênero e sexualidade, não estaria enfrentando um processo 
de "ugandização" do ponto de vista do que pode vir a ser a situação das minorias sexuais e de gênero neste país. Esta pergunta ganha relevância e atualidade num Brasil que está se tornando um terreno privilegiado de guerras culturais, onde questões de ordem moral, religiosa e de costume vêm assumindo um peso preponderante nos debates políticos. Deixamos estas questões em aberto para que possam instigar novas contribuições.

Recebido: 03/09/2020

Aprovado: 20/11/2020 


\section{Referências}

AWONDO, Patrick. Le sexe et ses doubles. (Homo)sexualités en postcolonie. Paris: ENS, 2019.

AWONDO, Patrick; GESCHEIRE, Peter; REID, GRAEME. Une Afrique homophobe? Sur quelques trajectoires de politisation de l'homosexualité: Cameroun, Ouganda, Sénégal et Afrique du Sud. Presses de Sciences Po., v. 1, n. 49, p. 95-118, 2013.

BACCHETTA, Paola; MAIRA, Sunaina; WINANT, Howard. Introduction. Global Raciality: Empire, PostColoniality, DeColoniality. In: Global Raciality: Empire, PostColoniality, DeColoniality. New York; London: Routledge, 2019.

BAKSHI, Sandeep; JIVRAJ, Suhraiya; POSOCCO, Silvia. Introduction. In: Decolonizing Sexualities. Transnational Perspectives, Critical Interventions. Oxford: Counterpress, 2016. p. 1-15.

bell hooks. E eu não sou uma mulher? Mulheres negras e feminismo. Rio de Janeiro: Rosa dos Tempos, 2019.

bell hooks. Ensinando a transgredir. A educação como prática de liberdade. São Paulo: Martin Fontes, 2013.

BLESSOL, Gathoni. LGBTI-Queer struggles like other struggles in Africa. In: EKINE, Sokari; ABBAS, Hakima. Queer African Reader. Dakar; Nairobi; Oxford: Pambazuka Press, 2013. p. 220-228.

CERVULLE, Maxime; REES-ROBERTS, Nick. Homo Exoticus. Race, classe et critique queer. Paris: Armand Collin, 2010.

COLLINS, Patricia Hill. Black Sexual Politics. African Americans, Gender and the New Racism. New York; London: Routledge, 2004.

COLLINS, Patricia Hill. Pensamento feminista negro. São Paulo: Boitempo, 2019.

COLY, A. Introduction (ASR Forum: Homophobic Africa). African Studies Review, v. 56, n. 2, p. 21-30, 2013.

CURRIER, Ashley, CRUZ, Joelle M. Religious inspiration: indigenous mobilization against LGBTI rights in post-conflict Liberia. In: van KLINKEN, Adriaan; CHITANDO, Ezra. Public Religion and the Politics of homosexuality in Africa. London; New York: Routledge, 2016.

DAVIS, Angela. Mulher, raça, classe. São Paulo: Boitempo, 2016.

DORLIN, Elsa. Le mythe du matriarcat noir. In: DORLIN, Elsa; FASSIN, Éric. Reproduire le genre. Paris: Bibliothèque Centre Pompidou, 2010.

EKINE, Sokari. Beyond Anti-LGBT Legislation: Criminalization and the Denial of Citizenship. In: BAKSHI, Sandeep; JIVRAJ, Suhraiya, POSOCCO, Silvia. Decolonizing Sexualities. Transnational Perspectives, Critical Interventions. Oxford: Counterpress, 2016. p. 19-31.

EKINE, Sokari. Contesting Narratives of queer Africa. In: EKINE, Sokari; ABBAS, Hakima. Queer African Reader. Dakar; Nairobi; Oxford: Pambazuka Press, 2013. p. 78-91.

EPPRECHT, Marc. Homosexual Africa? The History of an Idea from the Age of Exploration to the Age of AIDS (New African Histories). 2 ed. of

FASSIN, Éric. L'inversion de la question homosexuelle. Paris: Éditions Amsterdam, 2008.

GAGNON, Frédérick. Quelle guerre culturelle?: Les médias américains et Québécois et le 
mythe de la polarisation de la socieété americaine (Note). Études Internationales, v. LX, n. 3, p. 396-416, 2009.

GEVISSER, Marc. Homosexuality and the battle for Africa's soul. 2010b. Disponível em: https://mg.co.za/article/2010-06-04-homosexuality-and-the-battle-for-africas-soul

GEVISSER, Marc. Homosexuality and the Global Culture Wars. 2010a. Disponível em: http://www.markgevisser.com/images/pdf/homosexualityandtheglobalculturewars.pdf. Acesso em:

HARTMAN, Andrew. 2019. A War for the Soul of America. A History of the Culture Wars. Chicago and London: University of Chicago Press, 2008.

HERMAN, Didi. The Antigay Agenda. Orthodox Vision and the Christian Right. Chicago: University of Chicago Press, 1997.

HOAD, Neville. Sexual Intimacies. Race, Homosexuality and Globalization. Minneapolis; London: University of Minnesota Press, 2007.

KABWILA. Jessie. Seeing beyond colonial binaries: unpacking Malawi's homosexuality discourse. In: EKINE, Sokari; ABBAS, Hakima. Queer African Reader. Dakar; Nairobi; Oxford: Pambazuka Press, 2013. p. 376-392.

KAOMA, Kapya. An African or Um-African Sexual Identity? Religion, Globalisation and Sexual Politics in Sub-Saharan Africa. In: KLINKEN, Adrian van; CHITANDO, Ezra. Public Religion and the Politics of Homosexuality in Africa. London \& New York, 2016.

KAOMA, Kapya. Colonizing African Values. How the U.S. Christian Right is transforming sexual politics in Africa. Somerville, MA, USA: Political Research Associates. 2012.

KAOMA, Kapya. Globalizing the Culture Wars: U.S conservatives, African churches and homophobia. Somerville, MA, USA: Political Research Associates. 2009.

KAOMA, Kapya. The paradox and tension of moral claims: Evangelical Christianity, the politicization and globalization of sexual politics in sub-Saharan Africa. Critical Research on Religion, v. 2, n. 3, p. 227-245, 2014.

KATO, David Kisule. An essay. In: EKINE, Sokari; ABBAS, Hakima. Queer African Reader. Dakar; Nairobi; Oxford: Pambazuka Press, 2013. p. 6-8.

KLINKEN, Adriaan van. Culture Wars, Race and Sexuality: A Nascent Pan-African LGBT-Affirming Christian Movement and the Future of Christianity. Journal of Africana Religions, v. 5, n. 2, 2017.

KLINKEN, Adriaan van; CHITANDO, Ezra. Introduction: Christianity and the politics of homosexuality in Africa. In: CHITANDO, Ezra; van KLINKEN, Adriaan. Christianity and Controversies over Homosexuality in Contemporary Africa. Abingdon: Routledge, 2016.

KNIBBE, Kim. Movimentos religiosos transnacionais: de redes a territórios. Debates do NER, ano 10, n. 16, p. 35-47, 2009.

LIMA, Delcio Monteiro de. Os demônios descem do Norte. 5. ed. Rio de Janeiro: Francisco Alves, 1987.

LIVELY, Scott. Redeeming the Rainbow. A Christian Response to the "Gay" Agenda. Springfield: Veritas Aeterna Press, 2009.

LUGONES, Maria. Rumo a um feminismo descolonial. Revista Estudos Feministas, v. 22, n. 3. p. 935-952, 2014.

MACHARIA, Keguro. Homophobia in Africa is not a single Story, The Guardian, 26 de maio 2010.

MASSAD, Joseph. Avant-propos à la seconde étition. Politique de la via et épreuve du 
fratricide. In: MBEMBE, Achille. De la Postcolonie. Essai sur l'imagination politique dans l'Afrique contemporaine. Paris: Karthala, 2005.

MASSAD, Joseph. Desiring Arabs. Chicago: University of Chicago Press, 2007.

MBEMBE, Achille. Sair da grande noite. Ensaio sobre a África descolonizada. Luanda: Mulemba, 2014.

MIGUEL, Francisco. Maríyarapájis: Silêncio, exogamia e tolerância nos processos de institucionalização das homossexualidades masculinas no sul de Moçambique. Tese (Doutorado em Antropologia) - Universidade de Brasília, Brasília, 2019.

MSIBI, Thabo. The lies we have been told: on (Homo)sexuality in Africa, Africa Today, v. 58, n. 1, 2011.

MUTHIEN, Bernedette. Queerying borders: an Afrikan activist perspective. In: EKINE, Sokari; ABBAS, Hakima. Queer African Reader. Dakar; Nairobi; Oxford: Pambazuka Press, 2013. p. 211-219.

MWIKYA, Kenne. The media, the tabloid and the Uganda homophobia spectacle. In: EKINE, Sokari; ABBAS, Hakima. Queer African Reader. Dakar; Nairobi; Oxford: Pambazuka Press, 2013. p. 141-154.

NDASHE, Sibongile. The single story of African homophobia is a dangerous for LGBTI activism. In: EKINE, Sokari; ABBAS, Hakima. Queer African Reader. Dakar; Nairobi; Oxford: Pambazuka Press, 2013. p. 155-164.

NYANZI, Stella; KARAMAGI, Andrew. The social-political dynamics of the anti-homosexuality legislation in Uganda. Agenda: Empowering Women for Gender Equality, v. 29, n. 1, p. 30-32, 2015.

OLIVER, Marcia. Transnational Sex Politics, Conservative Christianity, and Antigay Activism in Uganda. Studies in Social Justice, v. 7, issue 1, p. 83-105, 2013.

OSSOME, Lyn. Postcolonial discourses of Queer Activism and Class in Africa. In: EKINE, Sokari; ABBAS, Hakima. Queer African Reader. Dakar; Nairobi; Oxford: Pambazuka Press, 2013. p. 32-47.

PELL, Rudolf Gaudio. Allah made us. Sexual outlaws in an Islamic African City. Chichester: Wiley Blackwell, 2009.

PUAR, Jasbir. Homonacionalismo como mosaico: viagens virais, sexualidades afetivas. Revista Lusófona de Estudos Culturais, v. 3, n. 1, p. 297-318, 2015.

PUAR, Jasbir. Terroristic Assemblages. Homonationalism in Queer Times. Durham: Duke University Press, 2007.

REA, Caterina. Descolonização, feminismos e condição queer em contextos africanos. Revista Estudos Feministas, v. 26, n. 3, p. 1-21, 2018.

REA, Caterina. Guerras culturais e novos imperialismos em contextos africanos: o trânsito da teoria Queer em meio ao novo conservadorismo cristão. Periodicus, n. 13, v. 2, p. 41-63, 2020.

REA, Caterina. Sexualidades dissidentes e teoria queer pós-colonial: o caso africano. Revista Epistemologias do Sul, v. 1, n. 1, p. 145-165, 2017.

REA, Caterina; AMANCIO, Izzie Madalena Santos. Descolonizar a sexualidade: teoria queer of color e trânsitos para o Sul. Cadernos Pagu, n. 53, p. 1-38, 2018.

SEGATO, Rita. Género y colonialidad: em busca de claves de lectura y de um vocabulário estratégico descolonial. In: BIDASECA, Karina; LABA, Vanesa Vazquez. Feminismos y poscolonialidad. Descolonizando el feminismo desde y em América latina. Buenos 
Caterina Alessandra Rea

Aires: Godot, 2011.

TAMALE, Sylvia. Confronting the Politics of Nonconforming Sexualities in Africa. African Studies, v. 56, n. 2, 2013.

TAMALE, Sylvia. Researching and theorising sexualities in Africa. In: TAMALE, Sylvia (Org.). African Sexualities. A Reader. Dakar; Nairobi; Oxford: Pambazuka Press, 2011. p. 11-36. 